\title{
Spreading of SARS-CoV-2 papers after first report. Reflections on scientific communication during the emergence of a new topic.
}

\author{
MICHELE MARIO CIULLA ${ }^{1,2}$, Patrizia Vivona ${ }^{3}$, and Elena Beranrdini ${ }^{3}$ \\ ${ }^{1}$ University of Milano \\ ${ }^{2}$ University of Milan \\ ${ }^{3}$ Affiliation not available
}

April 28, 2020

\begin{abstract}
The identification of novel SARS coronavirus in 2019 and the diffusion of COVID-19 prompted a new topic with an increased number of related scientific publications. Here we discuss the "spreading of papers" by analysing the first 60 papers following the "paper zero".
\end{abstract}

Spreading of SARS-CoV-2 papers after first report. Reflections on scientific communication during the emergence of a new topic.

Michele M Ciulla ${ }^{1,4}$, MD, PhD; Patrizia Vivona² MD, Elena Bernardini, PharmChemD ${ }^{3,4}$.

${ }^{1}$ Laboratory of Clinical Informatics and Cardiovascular Imaging; Department of Clinical Sciences and Community Health;

${ }^{2}$ Cardiology Unit, Vizzolo Predabissi Hospital, Vizzolo Predabissi, Italy

${ }^{3}$ Head Librarian, Biomedical Libraries,

${ }^{4}$ University of Milan, Milan, Italy

e-mail for correspondence: michele.ciulla@unimi.it

ORCID iD https://orcid.org/0000-0002-6717-6065

\section{Summary}

The identification of novel SARS coronavirus in 2019 and the diffusion of COVID-19 prompted a new topic with an increased number of related scientific publications. Here we discuss the "spreading of papers" by analysing the first 60 papers following the "paper zero".

\section{Introduction}

The identification of novel SARS coronavirus in 2019 (SARS-CoV-2) and the diffusion of the disease (COVID19) prompted a new emerging topic to the scientific community. As we know late December 2019, in China, were identified a limited number of patients hospitalised for unknown-caused pneumonia that were epidemiologically linked to a wholesale fish market in Wuhan, Hubei Province, China [1]. There are no doubt that, in such and other cases, commercial air travels and travellers have played a key role in the spreading SARS-CoV-2 [2]. Wuhan Tianhe International Airport is located around $26 \mathrm{~km}$ to the north of Wuhan city center. As at 21 February 2020 the virus had spread to "the Old Continent" [3]. At the emergence the reaction of media has led to a significant increase in the number of scientific publications on the subject 
which has affected not only thematic journals and, in some cases, the opening of online sections dedicated to the COVID-19. Since the spreading of papers follows the emergence of COVID-19 new cases with a cascade of new publications, the "spread of the virus" might be a test on the field to study the response time of scientific media following the abrupt emergence of a new theme like BMJ's Coronavirus Hub, JAMA network or COVID-19 Resource Centre by The Lancet. The World Health Organization created a database of publication on coronavirus disease that is update daily. The propagation of the virus is following by a spread of paper.

Our aim is to analyse the "travel" of this new topic by: 1-identifying and following the first report (paper zero) and the spreading all-over-the-word of the first 60 papers with reference of 2 -journal, theme and IF, 3 -research-country-of-origin, 4-time-to-acceptance and 5-time-to publishing by using as source PubMed and to compare it with the available data in non-emergency conditions.

\section{Methods}

The MEDLINE database was queried through PubMed, the public access web portal of the National Library of Medicine, National Institutes of Health-USA, in April 2020 by using the search query reported in the appendix. The total number of papers since the beginning $g$ of the year till now (12 April 2020) was obtained. Other databases such as Embase, Scopus and Web of Science - Core collection were also queried.

For our considerations we decided to focus on the first 60 papers retrieved from MEDLINE, after the paper zero, that was identified by following backward the series of published papers. Some descriptive statistics was used to support the discussion.

\section{Results}

The number of publications on SARS-nCov-2 and COVID-19 since the beginning of the year till now (13 April 2020) in MEDLINE were 4568; in Embase 2829, in Scopus 2201 while Web of Science - Core Collection 1081.

The paper zero, like the patient zero, is sometimes hard to be found, in such case doesn't exists as a conventional paper since is a mail posted on-line (Published Date: 2019-12-30 23:59:00) in the Program for Monitoring Emerging Diseases (ProMED) a public Internet service of the International Society for Infectious Diseases (ISID) [4]. Following the thread, the first non-scientific paper is a bulletin from the Wuhan Municipal Health Committee on the current pneumonia outbreak in the city [5].

In the match between journals, the first scientific paper has been published by Journal of Travel Medicine; the list of the first 60 papers, based on the date of publication, is reported in Table $\mathbf{1}$. Among the journals, a slight prevalence of non-thematic over thematic ones was found, respectively $55 \%$ vs $45 \%$. The papers were mostly original article $(50 \%)$, followed by reviews $(20 \%)$, case report $(16 \%)$, editorial $(10 \%)$, note $(8.3 \%)$ letter $(6.7 \%)$, viewpoint (4\%) (Table 2 ) and the country-of-origin of the first Author was China in 50\% of papers, at the second place, USA with $22 \%$, followed by 5 countries at $3,3 \%$, respectively, Korea, Italy, Sweden,T Germany and UK (Table 3 ). The mean \pm SD impact factor for these publications was $14 \pm$ 21; when considering the time-to, it was available only in 32 out of 60 records due to lack of transparency of some journals and/or publishers, they were surprisingly low since time-to-acceptance was $3 \pm 4$ days and the time-to-publishing $11 \pm 13$ days values not comparable with ordinary times [6]; no relations were found between IF and any of time-to. If we suppose that the lack of literature about COVID-19, initially named $2019 \mathrm{nCov}$ in January, is the cause of reducing the time required from submission to acceptance at the same time [6], we don't know if this ensures high quality standards in the review process. Between the 60 articles evaluated by our time-work over $85 \%$ are articles co-authored and it could be a reason to have a shorter time to publication but the difference in the reduction of the delay in publication are not explainable with this mechanism.

\section{Considerations}

When the scientific community are facing an emerging relevant topic like in the COVID-19 pandemia, it is 
possible to expect:

1- the lack of a paper zero, since the need to spread the information quickly let to use a self-posted messages that doesn't follow the submission rules of the scientific journals; this, undoubtedly, poses a problem for the conventional peer-review editorial model that might be bypassed by opting for a post-submission open-peer review model;

2- a significant increase in papers related to the new topic, also, in non-thematic journals, that is supported by the general clinical relevance reached by the topic and by the diffusion and prestige of the journals itself that are, possibly, likely to mobilise more resources for the editorial processes during emergencies; as in other studies, the IF itself doesn't seems to affect the ranking but there is a remarkable number of high IF journals;

3- a prevalence of papers coming from the geographical area where the emergency starts, in such case China, and, in case of diffusion, an expansion to others country that tracks the pandemia, with a crawling of case report like a signal of new focuses of infection in other countries;

4- an initial significant reduction in time-to-acceptance and time-to-publish, if compared with standard ones, that, evidently, is supported by an extra effort of editors and reviewers to follow the emergence of the new topic; we don't know weather if, this increase of speed, can be satisfied by maintaining the same quality standards and if, after the emergency, the increased submission of papers might represent a bottle neck with a negative impact on the publishing times.

\section{Appendix: search query.}

("Coronavirus"[Mesh:NoExp] OR "Betacoronavirus"[Mesh] OR "Coronavirus Infections" [Mesh:NoExp] OR "Severe Acute Respiratory Syndrome" [Mesh] OR "COVID-19 vaccine" [Supplementary Concept] OR "COVID19 serotherapy" [Supplementary Concept] OR "spike glycoprotein, COVID-19 virus" [Supplementary Concept] OR "COVID-19" [Supplementary Concept] OR "COVID-19 drug treatment"[Supplementary Concept] OR "COVID-19 diagnostic testing" [Supplementary Concept] OR "severe acute respiratory syndrome coronavirus 2" [Supplementary Concept]) OR (((( "severe acute respiratory syndrome coronavirus 2" [Title/Abstract] OR "SARS-Related Coronavirus" [Title/Abstract] OR "sars virus" [Title/Abstract] OR "sars viruses" [Title/Abstract] OR betacoronavirus[Title/Abstract]))) OR ((COVID19[Title/Abstract] OR Covid-19[Title/Abstract] OR SARS-CoV-2[Title/Abstract] OR 2019-nCoV[Title/Abstract] OR SARS2[Title/Abstract] OR SARS-CoV19[Title/Abstract] OR coronavirus*[Title/Abstract]))) OR ((Pneumonia[Title/Abstract]) AND (outbreak*[Title/Abstract] OR atypic*[Title/Abstract] OR wuhan[Title/Abstract]))) AND (2020:2020[pdat]) Filters: from 2020 - 2020

\section{References}

[1] Zhu N, Zhang D, Wang W, et al; China Novel Coronavirus Investigating and Research Team. A Novel Coronavirus from Patients with Pneumonia in China, 2019. N Engl J Med. 2020 Feb 20;382(8):727-733. doi: 10.1056/NEJMoa2001017. Epub 2020 Jan 24. PubMed PMID: 31978945; PubMed Central PMCID: PMC7092803.

[2] Wilson ME, Chen LH. Travellers give wings to novel coronavirus (2019-nCoV). J Travel Med . 2020;27(2):taaa015. doi:10.1093/jtm/taaa015

[3] Spiteri G, Fielding J, Diercke M, et al.. First cases of coronavirus disease 2019 (COVID-19) in the WHO European Region, 24 January to 21 February 2020. Euro Surveill. 2020 Mar;25(9). doi: 10.2807/15607917.ES.2020.25.9.2000178. PubMed PMID: 32156327; PubMed Central PMCID: PMC7068164.

[4] Undiagnosed pneumonia - China (HU). ProMED. Archive Number: 20191230.6864153; Published Date: 2019-12-30 23:59:00. https://promedmail.org/promed-post/?id=6864153

[5] Wuhan Municipal Health Committee: briefing on the current pneumonia outbreak in our city. Wuhan Municipal Health Committee. Published Date: 2019-12-31 13:38:05. http://wjw.wuhan.gov.cn/front/web/showDetail/201912310

[6] Toroser D, Carlson J, Robinson M, et al. Factors impacting time to acceptance and publication for peerreviewed publications. Curr Med Res Opin. 2017;33(7):1183-1189. doi:10.1080/03007995.2016.1271778 
Table 1

\begin{tabular}{|c|c|c|c|c|c|c|c|c|}
\hline $\begin{array}{l}\text { Ran- } \\
\text { King }\end{array}$ & Journal name & Theme & IF & $\begin{array}{r}\text { TA mean } \\
\text { (d:h) }\end{array}$ & TP mean (d:h) & $\begin{array}{l}\text { Total pa- } \\
\text { pers }\end{array}$ & $\begin{array}{l}\text { Original } \\
\mathrm{n}^{\circ}\end{array}$ & Original \% \\
\hline 1 & Journal of Travel Medicine & $\mathrm{N}$ & 4.155 & $2: 0$ & $6: 0$ & 1 & 0 & 0,0 \\
\hline 2 & Journal of Medical Virology & Y & 2.049 & 7:12 & 13:16 & 7 & 5 & 71,4 \\
\hline 3 & NEJM & $\mathrm{N}$ & 70.670 & 2:0 & $57: 0$ & 8 & 2 & 25,0 \\
\hline 4 & Viruses & r & 3.811 & 1:12 & 1:12 & 2 & 0 & 0,0 \\
\hline 5 & Lancet & $\mathrm{N}$ & 59.102 & na & na & 8 & 6 & 75.0 \\
\hline 6 & Emerging Microbes \& Infections & Y & 6.212 & 1:16 & 7:0 & 3 & 0 & 0,0 \\
\hline 7 & Eurosurveillance & Y & 7.421 & 4:0 & 4.6 & 6 & 5 & 83,3 \\
\hline 8 & Nature & $\mathrm{N}$ & 43.070 & $10: 0$ & 13:18 & 4 & 0 & 0,0 \\
\hline 9 & Journal of Virology & r & 4.324 & 6:0 & $55: 0$ & 1 & 1 & 100,0 \\
\hline 10 & Bioscience Trends & $\mathrm{N}$ & 1.686 & 4:0 & 5:0 & 1 & 1 & 100,0 \\
\hline 11 & Journal of Korean Medical Science & $\mathrm{N}$ & 1.716 & 2:0 & 3:0 & 2 & 0 & 0,0 \\
\hline 12 & JAMA & $\mathrm{N}$ & 51.273 & 2:0 & 3:0 & 2 & 0 & 0,0 \\
\hline 13 & Journal of Infection & r & 5.099 & na & na & 1 & 0 & 0.0 \\
\hline 14 & Radiology & $\mathrm{N}$ & 7.608 & 2:12 & $5: 12$ & 2 & 2 & 100,0 \\
\hline 15 & Infection Genetics and Evolution & Y & 2.611 & 1:12 & 2:12 & 2 & 0 & 0.0 \\
\hline 16 & Travel Medicine and Infectious Disease & r & 4.868 & 3:0 & 5:0 & 2 & 1 & 50,0 \\
\hline 17 & International Journal of Infectious Diseases & r & 3.538 & 0:0 & $34: 0$ & 2 & 1 & 50,0 \\
\hline 18 & Science China Life Sciences & $\mathrm{N}$ & 3.583 & 4:0 & 5:0 & 1 & 0 & 0.0 \\
\hline 19 & Cell Res & $\mathrm{N}$ & 17.848 & 3:0 & $10: 0$ & 1 & 0 & 0,0 \\
\hline 20 & Chemibiochem & $\mathrm{N}$ & 2.641 & 8:0 & 8:0 & 1 & 0 & 0.0 \\
\hline 21 & Microbes Infections & r & 2.669 & 1:0 & 7:0 & 1 & 0 & 0,0 \\
\hline 22 & World Journal of Pediatrics & $\mathrm{N}$ & 1.169 & 1:0 & 9:0 & 1 & 0 & 0,0 \\
\hline
\end{tabular}

Legend: Ranking $=$ order of publication date; Theme $=$ Journal's theme; IF = Impact Factor by JCI $;$ TA = Time-to-Acceptance, days:hours $;$ TP = Time-to-Publishing, days:hours; Total papers $=$ Original $n^{\circ}=$ Original Articles, $n^{\circ} ;$ Original \% $=$ Original Articles, \% of Total papers $; n a=n o t$ available data. 
Table 2

\begin{tabular}{|l|r|r|}
\multicolumn{4}{|c}{ Papers } \\
\hline
\end{tabular}

Table 3

\begin{tabular}{|l|r|r|}
\hline Country & papers first Author & \multicolumn{1}{l}{ Country \% } \\
\hline China & 30 & 50,0 \\
\hline USA & 13 & 21,7 \\
\hline Korea & 2 & 3,3 \\
\hline Italy & 2 & 3,3 \\
\hline Sweden & 2 & 3,3 \\
\hline Germany & 2 & 3,3 \\
\hline UK & 2 & 3,3 \\
\hline Argentina & 1 & 1,7 \\
\hline Netherlands & 1 & 1,7 \\
\hline Greece & 1 & 1,7 \\
\hline Switzerland & 1 & 1,7 \\
\hline Vietnam & 1 & 1,7 \\
\hline Argentina & 1 & 1,7 \\
\hline Canada & 1 & 1,7 \\
\hline & 60 & 100,0 \\
\hline
\end{tabular}

